\title{
Supercritical water oxidation of octol - containing wastewater
}

\author{
Gurbulak E. ${ }^{1, *}$, Yuksel E. ${ }^{1}$, Tekbas M. ${ }^{1}$, Doruk T. ${ }^{2}$, Eyvaz M. ${ }^{1}$, Bektas N. ${ }^{1}$ \\ ${ }^{1}$ Gebze Technical University, Department of Environmental Engineering, 41400, Kocaeli, Turkey \\ 2Ondokuz Mayıs University, Department of Molecular Biology and Genetics, 55105, Samsun, Turkey \\ Received: 23/05/2018, Accepted: 12/02/2019, Available online: 15/02/2019 \\ *to whom all correspondence should be addressed: e-mail: egurbulak@gtu.edu.tr
} https://doi.org/10.30955/gnj.002776

\section{Abstract}

This study investigated optimum operating conditions of supercritical water oxidation (SCWO) for octol and compared the degradation of its components TNT $(2,4,6$ trinitrotoluene) and $\mathrm{HMX}$ (octahydro-1,3,5,7-tetranitro1,3,5,7-tetrazocine, octogen) under the same conditions. Pilot scale experiments were conducted at various temperatures, reaction times and oxidant amounts. Removal efficiency, by-product analysis and toxicity tests were selected as the performance criteria for the SCWO. Optimum conditions were determined as a temperature of $500{ }^{\circ} \mathrm{C}, 120 \mathrm{~s}$ of oxidation time and an oxidant ratio of $150 \%$. Removal of octol was achieved at a rate of $99.99 \%$, while TNT and HMX were removed individually at a rate of $\sim 85 \%$ when they existed in the wastewater. No toxicity was observed at the end of the octol oxidation, whereas toxicity was found in the TNT and HMX oxidation due to the formation of TNT isomer and aniline. Higher initial organic material concentrations promoted the removal rates. These results demonstrated that SCWO can be effectively used for the degradation of ammunition wastewater even when concentrations are high.

Keywords: Supercritical water oxidation, ammunition wastewater, octol, TNT, HMX, toxicity.

\section{Introduction}

For the past 50 years, one of the most important research areas of the defense industry has been the production of lighter and less space-consuming warheads and longrange weapons. To this purpose, ammunition with high detonation velocity was produced using explosives such as TNT (2,4,6-trinitrotoluene) and HMX (octahydro-1,3,5,7tetranitro-1,3,5,7-tetrazocine, octogen) in different combinations.

Octol is an explosive which has one of the highest detonation velocities. It is manufactured by the casting of water-wet HMX and molten TNT in order to meeting the requirements in question. Moreover, the production process and utilization performance have been well known for many years. An additional advantage is that it can be produced in desired shapes and sizes (Hussein et al., 2018).
Considering both the dramatic increase in octol use and the nitro aromatic and heterocyclic nitramine groups in its structure, it has become a non-negligible nitro-compound source of pollution (Chatterjee et al., 2017). This pollution has harmful effects on the environment and health due to its characteristic of persistent resistance to biological degradation (Snellinx et al., 2002). Jong et al. (2006) determined that $\mathrm{HMX}$ had a more recalcitrant structure than other well-known explosives including TNT and RDX. Although 2,4,6 TNT has potential carcinogenic effects, its transformation products have adverse effects on the central nervous system of mammals (ATSDR, 1995; Falone et al., 2006). Similarly, the US Environmental Protection Agency (EPA, 1988) has stated that HMX has potential toxic properties which can lead to focal atrophic changes in the the liver and kidneys and can also affect the functioning of these organs (ATSDR, 1997). In addition, Panz et al. (2013) stated that compared to individual substances, explosive mixtures exhibited more synergetic toxic effects. It has been determined that TNT and HMX in amounts of over $2 \mu \mathrm{g} / \mathrm{L}$ and $400 \mu \mathrm{g} / \mathrm{L}$, respectively, in drinking water have a negative effect on human health (Chatterjee et al., 2017).

Several studies have reported on the outcome of such pollutants and on the limitations of their control and disposal techniques. Physical separation methods such as adsorption and membrane techniques have some limitations because of high operation costs and the secondary pollutants that occur during the treatment processes (Rodgers and Bunce, 2001; Nehrenheim and Odlare, 2008). Advanced oxidation methods focus mainly on photo catalytic and fenton oxidation, which are relatively uneconomical and concentration dependent methods with lengthy reaction times (Son et al., 2004). A number of studies in the literature have also investigated the biological degradation of explosives. Moshe et al. (2009) indicated that TNT had a negative effect on the biodegradation of HMX. Namely, when there is TNT in a mixture, the degradation products of TNT inhibit HMX degradation. Consequently, these treatment methods not only fail to meet legal effluent standards, but also lead to the formation of toxic degradation products (Chang and Liu, 2007). 
In the search for ways to uncompromisingly satisfy effluent standards and fill the need for sustainable and greener waste treatment technologies, supercritical water oxidation (SCWO) technology has been gaining importance because the reaction by-products from its processing are harmless and its short reaction times and high treatment efficiency. Thus, SCWO is a promising organic waste treatment technology is carried out above the critical point of water $\left(\mathrm{TC}=374.3^{\circ} \mathrm{C}, \mathrm{Pc}=22.1 \mathrm{MPa}\right)$. Under these conditions, by decreasing the density and dielectric constant of the water, the hydrogen bonds are reduced, which results in water with the high diffusivity and excellent transfer characteristic of a non-polar medium. In this case, organic matter, oxygen and water at all proportions become miscible and form a single homogeneous system. Based on these supercritical water properties, the reaction takes place almost completely $(>99.9 \%)$ and the reaction time is very short, generally from just a few seconds to a few minutes, because there is no interphase mass transfer resistance (JimenezEspadafor et al., 2011). As a consequence, organic materials are oxidized into harmless products and inorganic compounds into a gas or solid phase (Zhang et al., 2017).

In recent studies, optimum treatment conditions have been clearly determined and degradation mechanisms have been defined for many types of industrial hazardous wastes using SCWO (Vadillo et al., 2014; Qian et al., 2016). The SCWO process, therefore, is considered as an alternative to incineration systems in terms of operating costs, lack of hazardous by-products and disposal (Marulanda and Bola, 2010). Moreover, supported by technological developments, the installment of industrialscale SCWO systems has come to the forefront and SCWO is being promoted as an emerging treatment technology in European directives (Brinkmann et al., 2016).

There are few studies examining the degradation of explosives, as compared to other waste types, using SCWO. In these studies, the degradation mechanism and the optimum recovery rate were determined for a single waste type. Chang and Liu (2007) reported that TNT was degraded with $99.9 \%$ efficiency at $550{ }^{\circ} \mathrm{C}$ and $240 \mathrm{MPa}$ in $120 \mathrm{~s}$ with $300 \%$ of excess oxygen, whereas Zhao et al. (2008) claimed that the COD removal efficiency of $\mathrm{HMX}$ exceeded $99 \%$ under conditions of $450-590{ }^{\circ} \mathrm{C}, 23 \mathrm{MPa}$ and $300 \%$ of excess oxygen in $20 \mathrm{~s}$. Similarly, Buelow et al. (2002) reported that TNT and HMX degraded individually at $600{ }^{\circ} \mathrm{C}$ in $10 \mathrm{~s}$ at half of their water solubility concentrations. These various experimental results obtained from different studies demonstrated that temperature and residence time are important parameters affecting degradation efficiency and that further studies are required to determine the exact optimum operating conditions for achieving higher degradation efficiency within feasible operation costs. Most importantly, to the best of our knowledge, to date, there has been no other SCWO study on the degradation of wastes of mixtures including nitro aromatic and nitro heterocyclic explosives.
The main objective of this study was to determine, for the first time, the optimum operating conditions of SCWO for the degradation of octol, which is a mixture of nitro aromatic and nitro heterocyclic compounds. Moreover, the SCWO removal efficiency for octol was compared with the efficiency of the individual treatments of TNT and HMX. Toxicity tests were also carried out for SCWO by-products in order to further evaluate the environmental impact of the explosive removal technique.

\section{Materials and methods}

\subsection{Chemicals and standards}

Octol (Purity 98\%), TNT and HMX explosives used in this study were obtained from the Mechanical and Chemical Industry Company (MKE) and the Scientific and Technological Research Council of Turkey (TUBITAK), respectively. Hydrogen peroxide $\left(\mathrm{H}_{2} \mathrm{O}_{2}\right)(50$ wt. \% in aqueous solution) and chromatographic grade methanol were purchased from Sigma Aldrich. The TNT and HMX standards were also obtained from Dr. Ehrenstorfer $\mathrm{GmbH}$.

\subsection{Preparation of synthetic wastewater}

Since dissolutions of TNT and HMX in water is difficult, the solutions were first prepared by dissolving the appropriate amount of each explosive in methanol. The HPLC analyses were performed without any interference because the methanol was used as the carrier solvent. After adding the prepared methanol mixture to boiling tap water, the methanol was evaporated off in order to obtain the desired concentration of synthetic wastewater (Alnaizy and Akgerman, 1999).

\subsection{Analytical methods}

\subsubsection{HPLC}

The composition analyses of the explosive wastewater and effluents were performed using a Thermo Finnigan Surveyor high-pressure liquid chromatograph (HPLC) equipped with a variable wavelength UV detector. The chromatographic column was $\mathrm{C} 18,25 \mathrm{~cm} \times 4.6 \mathrm{~mm}, 5$ $\mu \mathrm{m}$. For the mobile phase, the methanol: water ratio was 50:50, with $1 \mathrm{~mL} / \mathrm{min}$ of flow rate. For each experiment, $20 \mu \mathrm{l}$ of the sample was injected into the column at room temperature. The detector wavelength was $254 \mathrm{~nm}$.

\subsubsection{GC-MS/MS}

By-product analyses were carried out in a TSQ $^{\text {TM }} 9000$ Triple Quadrupole GC-MS/MS System. Separations were performed using a TraceGOLD TG-5MS $30 \mathrm{~m} \times 0.25 \mathrm{~mm} \times$ $0.25 \mu \mathrm{m}$ column. The total $\mathrm{GC}$ run time was $32.34 \mathrm{~min}$. Helium in a constant flow mode at $1.3 \mathrm{~mL} / \mathrm{min}$ was used as the carrier gas. The mass spectrometer was operated in Electron ionization mode (EI) using the selected reaction monitoring (SRM) mode for each compound.

\subsubsection{Microbial toxicity assays}

The toxicity was evaluated by employing the recombinant luminescent strain Escherichia coli $\mathrm{DH} 5 \alpha$ with the cloned IUxCDABE genes of Photorhabdus luminescence. The cultures of recombinant $E$. coli strains were harvested in the exponential phase and washed with saline solution 
$(0.9 \% \mathrm{NaCl})$. The cells were re-suspended in the solution to determine the optical density at $600 \mathrm{~nm}$ (OD600) with 0.4 increments, which correspond to approximately $108 \mathrm{cfu} / \mathrm{mL}$. Then, $190 \mu \mathrm{L}$ of bacterial suspension was transferred to 96-well white plates (UltraCruz, Flat Bottom) and mixed with $10 \mu \mathrm{L}$ of test sample. The light emission of the recombinant $E$. coli strain was recorded after 10 min to $6 \mathrm{~h}$ by using FLUOstar Omega Microplate Reader (BMG LABTECH, USA) and the results were expressed as relative light units (RLU).

\subsection{Experimental method}

\subsubsection{SCWO system}

A schematic diagram of the SCWO system is given in Figure 1. A laboratory scale plug flow system consisting of four main parts including high pressure reactor and tubing, a high pressure pump, a heater and a heat control system was used for degradation of the simulated munitions wastewater. The SCWO reactor (1) having a volume of $5 \mathrm{~L}$ was made of stainless steel (SS 310). Sealing on the pipeline and reactor was provided by using certified high-pressure fittings. The wastewater was pumped to the reactor from a $50-\mathrm{L}$ volume wastewater feeding tank (2) equipped with a controllable mixer unit for homogenizing the wastewater. A positive displacement diaphragm high-pressure pump (3) with adjustable flow between $0-2 \mathrm{~L} / \mathrm{min}$ was employed to maintain a constant high pressure (up to 300 bar) and flow for the effective transfer of all kinds of wastewater. Check valves were placed in the line to prevent back streaming in case of pump failure. The oxidizer was injected from the oxidant tank (4) into the wastewater via the peristaltic pump (5) before the high-pressure pump in order to ensure a complete mixing before entering the heated part of the reactor. A thermostat-controlled ceramic base heater (6) was utilized to reach the required temperature within $\pm 1{ }^{\circ} \mathrm{C}$ precision. The temperature was monitored with $\mathrm{K}$ type thermocouples (TE) at three different points on the reactor, and three points throughout the pipeline (at the inlet line and before and after the cooling zone) to control reaction conditions and ensure safety. Moreover, the system pressure was measured, controlled and kept constant by a gauged manometer (PI) and pressure relief valve, respectively. After the pressure was reduced, the effluent was lowered to a suitable temperature via water and air cooler systems $(7,8)$. At the end of the process, the liquid and gas phases were separated from each other by a liquid-gas separator (9).

\subsubsection{Experimental procedure}

Prior to each startup, tap water was pumped into the reactor for fifteen minutes so that the pressure, temperature and the flow in the system could reach steady state conditions. Thereafter, the experiments were performed. In order to provide reliable data acquisition, after each experiment, the reactor and the connected tubing were cleaned using pressurized tap water.

Many runs were performed at various temperatures, retention times and oxidant concentrations in order to determine the optimum treatment conditions for octol removal. The temperature range selected was between 400 and $600{ }^{\circ} \mathrm{C}$ and the operation pressure was set at the single pressure of $25 \mathrm{MPa}$ because, many researchers have confirmed that the influence of pressure on SCWO is small when it exceeds the critical pressure of water (22.12 MPa) (Segond et al., 2002). Even this influence can be negligible compared with that of the reaction temperature (Segond et al., 2002; Xie, 2015).

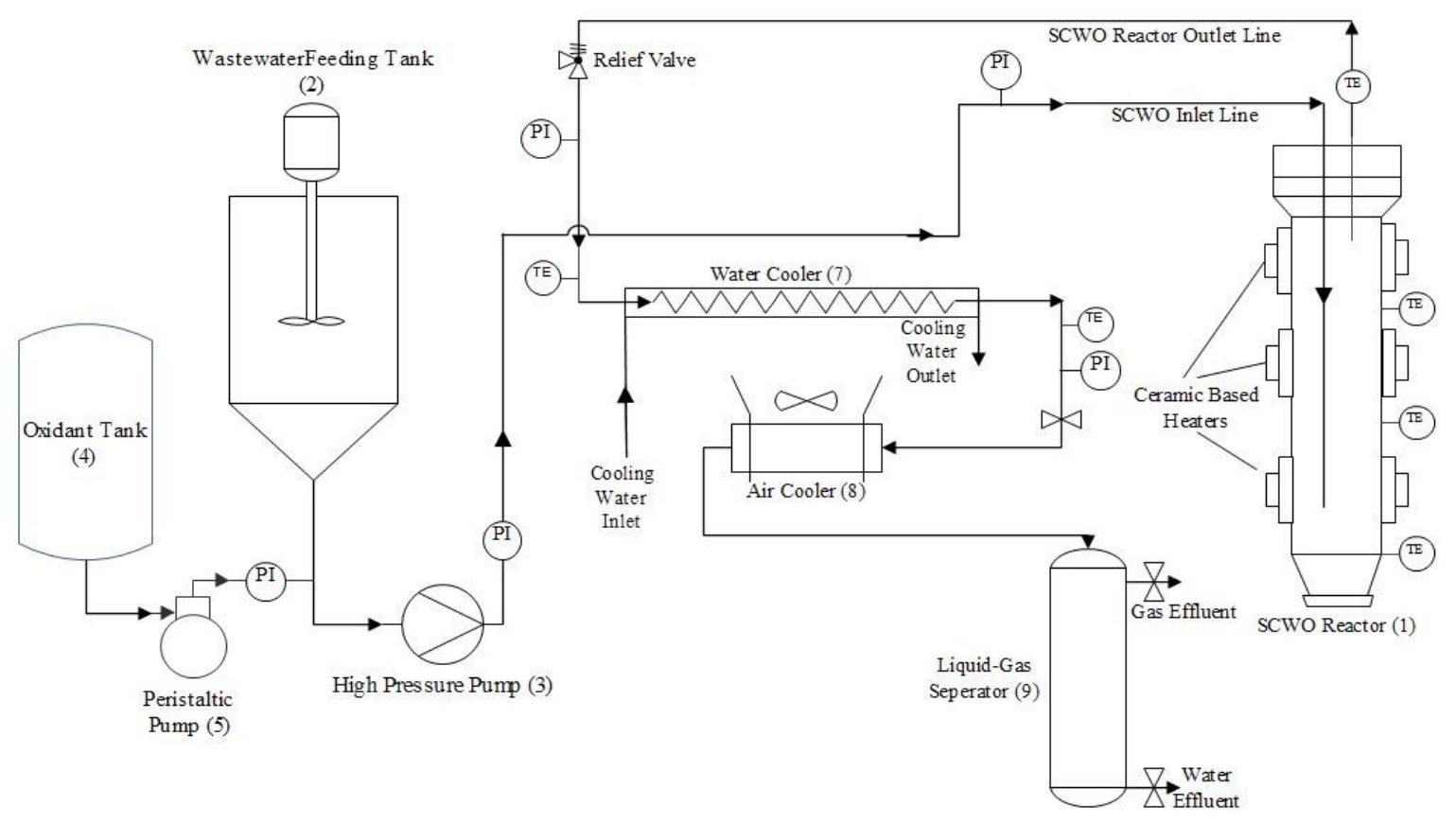

Figure 1. Pilot-scale SCWO System 
The selected retention time was between 10 and $180 \mathrm{~s}$. Here, the time was adjusted by the control of the pump flow rate, which was calculated using Equation (1).

$$
Q=\frac{V}{\tau} \frac{\rho_{o}}{\rho}
$$

where $Q$ is the flow rate of the feed at ambient temperature and pressure $\left(\mathrm{L} \mathrm{s}^{-1}\right), \mathrm{V}$ is the volume of the reactor $(L), \tau$ is the reaction retention time $(s), \rho_{o}$ is the density of fluid at ambient temperature and pressure $(\mathrm{mg}$ $\mathrm{L}^{-1}$ ) and $\rho$ is the density of fluid in the SCWO reactor ( $\mathrm{mg} \mathrm{L}^{-1}$ ). Here, $\rho$ was calculated using the Peng-Robinson equation which can be found elsewhere in the literature.

Finally, as the third system parameter, the oxidant coefficient of between 1 and 3 was chosen. Hydrogen peroxide was used as the oxygen source. Many researchers have noted that hydrogen peroxide completely decomposed to oxygen because of the high decomposition rate under high temperatures and pressures (Croiset et al., 1997; Rice, 1996). The oxidant coefficient was determined according to TOC measurement of wastewater.

The required amount of $\mathrm{H}_{2} \mathrm{O}_{2}$ was determined according to the stoichiometric reaction below:

$$
\mathrm{H}_{2} \mathrm{O}_{2} \stackrel{k}{\rightarrow} \mathrm{H}_{2} \mathrm{O}+\frac{1}{2} \mathrm{O}_{2}
$$

The optimum experimental conditions obtained from the octol experiments were also applied for both TNT and HMX removal separately in order to evaluate whether or not the mixing of explosives affected the SCWO performance. All experiments were conducted in three replications to calculate the mean value and standard deviations and shown in the figures.

\section{Results and discussion}

\subsection{Optimum parameters for octol degradation}

In this study, all the experiments were carried out under different temperatures, residence times and oxidant concentrations as experimental factors for the SCWO process. Removal efficiency, degradation by-products and toxicity results were selected as the performance criteria. Many researchers have reported that the temperature and residence time are the most important operating parameters affecting the degradation efficiency of wastes in the SCWO process. The temperature and residence time were evaluated simultaneously. The aforementioned criteria were investigated at six different temperatures (between $374-600{ }^{\circ} \mathrm{C}$ ) and residence times (45-180 s). In addition, oxidant concentrations were studied at different oxidant coefficient (100-300\%).

The influence of temperature and residence time on octol decomposition is shown in Figure 2 under the conditions of 250 bar pressure and $150 \%$ excess oxygen $\left(\mathrm{O}_{2}\right)$. The degradation efficiency of HMX and TNT in the octol structure increased with the temperature, which is consistent with the literature. Because the water was turned into a strong solvent by decreasing its dielectric constant depending on temperature increases under supercritical conditions, it boosted the solute-solvent reactions resulting in the decomposition of the organic compounds in the wastewater (Wang et al., 2011; Cui et al., 2009). On the other hand, the increase in temperature also originated from the decrease of water density. For this reason, the relative concentration of pollutants actually decreased with increasing temperature. Therefore, it was expected that the increase in the reaction rate would decrease after a certain temperature value was reached.

The effects of the retention time were also investigated using $150 \%$ excess oxygen at a pressure value of 250 bar. According to Figure 2, the degradation rate continuously increased with reaction time increase until a certain value was reached, and then stayed nearly constant at higher retention times. Similar faster conversions of organic compounds under supercritical water oxidation conditions have been reported in the literature (Cui et al., 2009).

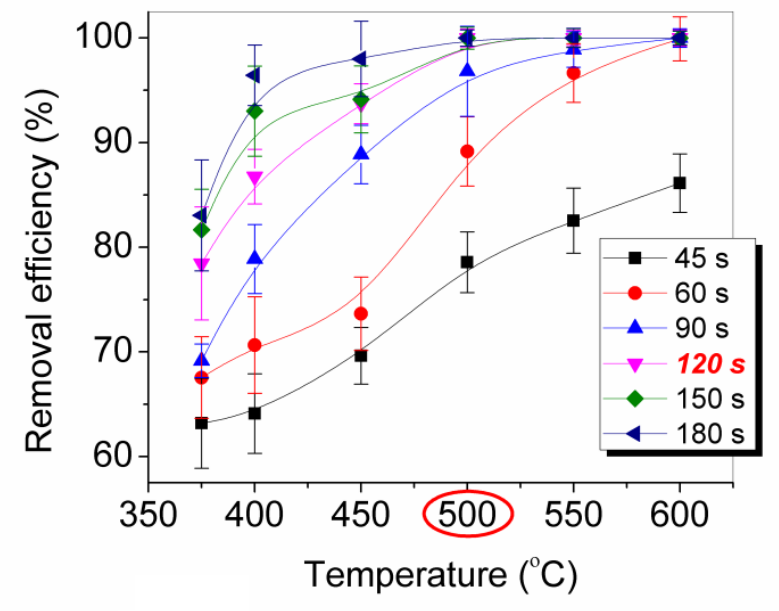

(a)

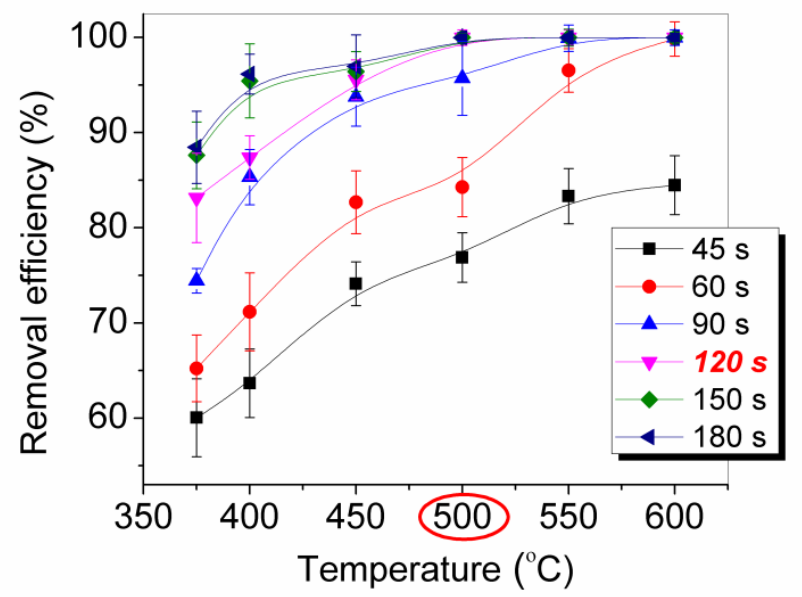

(b)

Figure 2. Effects of temperature and residence time on the removal of (a) HMX in octol and (b) TNT in octol 
As expected, it may be concluded from the very small amounts of remaining (undetectable) oxidant and organic materials that the reaction would continue the slow conversion of organics in further residence times.

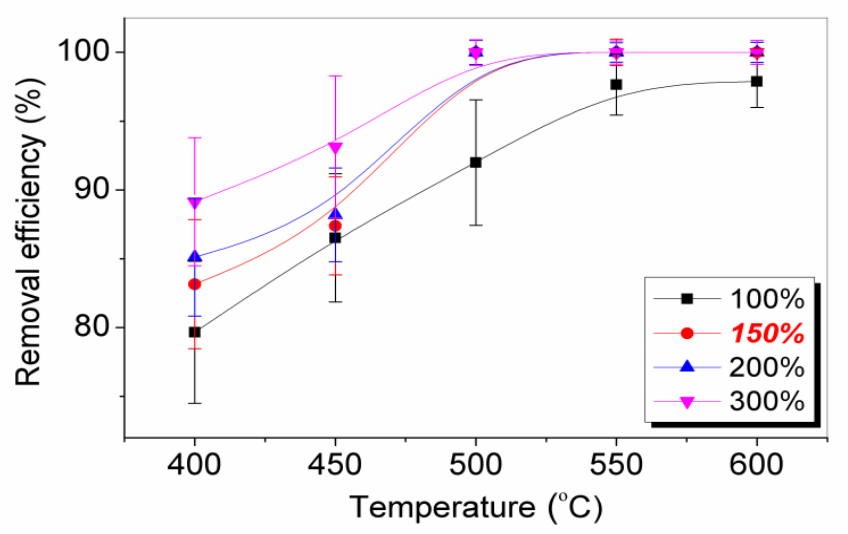

(a)

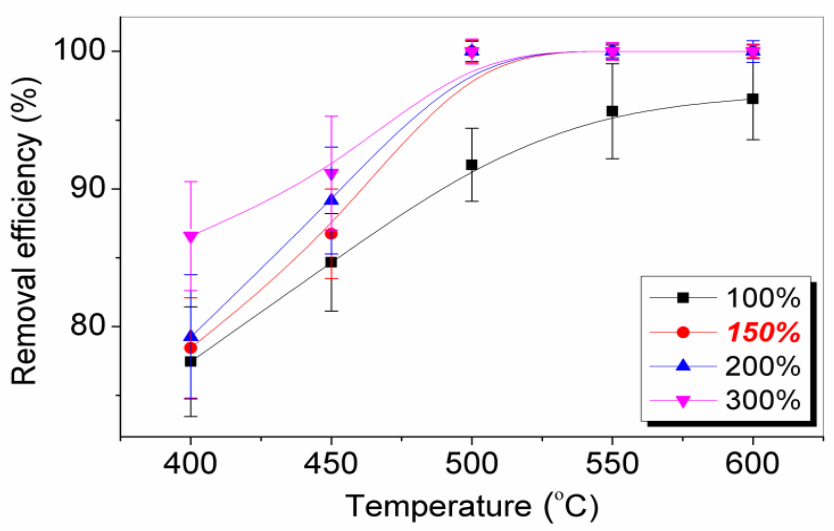

(b)

Figure 3. Effects of different oxidant coefficients on the removal of octol components at 250 bar, $500{ }^{\circ} \mathrm{C}$ and for $120 \mathrm{~s}$; (a) for $\mathrm{HMX}$, (b) for TNT

The oxidation coefficient is another important operating parameter for SCWO. There is a need to add a sufficient amount of oxidant to complete the removal of octol. The oxidation coefficient (\%) could be used quantitatively to reflect the supplied oxidant amount in the reaction processes. It was calculated as the theoretical $\mathrm{H}_{2} \mathrm{O}_{2}$ (oxidant) amount required for the complete degradation of the initial concentration.

Figure 3 shows the effect of the different oxidation coefficients on the removal efficiency of octol components. As seen from Figure 3, oxidant addition increased the removal rate of octol, hence the oxidant promoted the decomposition of octol. As expected, however, further increases in oxidant amount did not affect octol removal. Regarding the maximum degradation efficiency (99.99\%), a pressure of 250 bar, 120 s of residence time and a temperature of $500{ }^{\circ} \mathrm{C}$ were selected as the optimum operating conditions. Analyses of degradation by-products and toxicity tests were carried out under the optimum experimental conditions. According to Table 1, trace amounts of one-ring-aromatics occurred with the highest yields of octadeanoic acid and 13 Docosenamide, which are not refractory substances. The formation of these intermediates addressed the hydrolysis reaction pathways. Ding et al. (1996) stated that these reaction pathways strongly depended on temperature, organic/oxygen concentration ratio and ionic strength. It may be concluded that the simultaneous reactions indicated that TNT and HMX showed effects on each other in view of increases in both temperature and oxygen concentration.

Table 1. By-products of octol degradation by SCWO

\begin{tabular}{ccc}
\hline By-Products & Retention Time (min) & Peak Area Ratio \\
\hline Hexadecanoic Acid & 18.05 & 1.73 \\
\hline Octadecanoic Acid & 24.42 & 7.65 \\
\hline 1,3-Docosenamide & 24.88 & 14.89 \\
\hline
\end{tabular}

Toxicity experiments were conducted for both raw and treated samples. Figure 4 shows the variation of the toxicity during octol degradation under conditions of 250 bar pressure, $500{ }^{\circ} \mathrm{C}$ and $150 \%$ excess oxygen with respect to residence time. According to the results at the end of the degradation process, the toxicity of the treated samples was remarkably lower than that of the wastewater. The light emission from recombinant $E$. coli cells decreased dramatically when the raw wastewater was considered. However, the toxicity decreased for the treated samples depending on increasing residence time.
At optimum conditions and at higher values of time, temperature and oxidant concentration, the toxicity assay test showed no toxicity against recombinant $E$. coli cells, even after $6 \mathrm{~h}$. These results demonstrated that, due to the high degradation rate and very low toxicity level, the SCWO process can be effectively used for octol degradation. Most importantly, although the synergistic toxic effects of the TNT/HMX mixtures were more pronounced as indicated by Panz et al. (2013), the SCWO also showed superior performance in the toxicity reduction of these substances. 


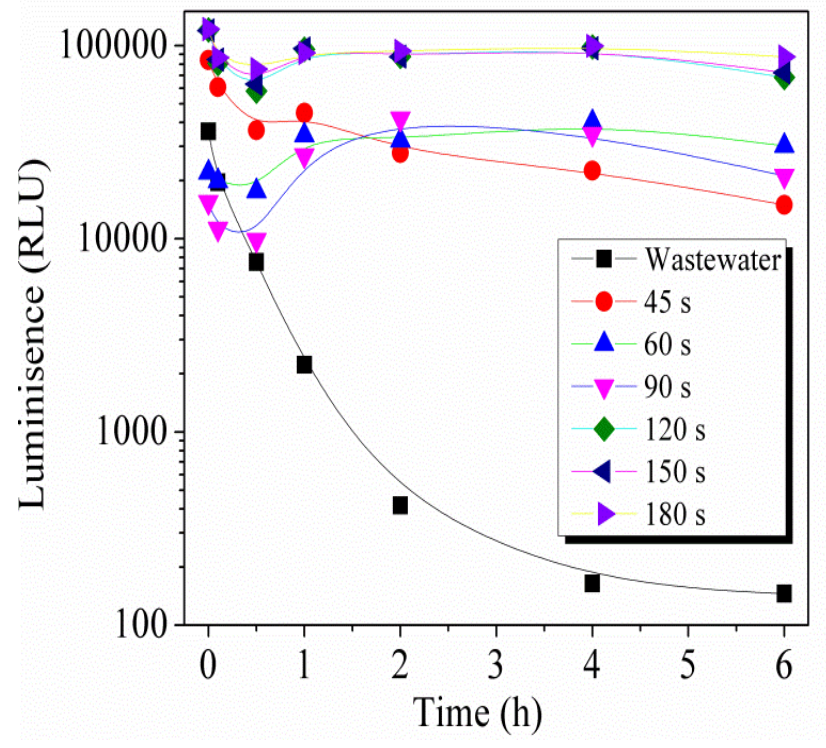

Figure 4. Results of microbial toxicity assay for octol degradation

3.2. Comparison of removal efficiency of octol and separate TNT and HMX

The separate forms of TNT and HMX obtained under optimum operating conditions from octol removal experiments were monitored in terms of degradation efficiency, toxicity and by-products. In the experiments which were conducted with the octol component separately, the degradation efficiency of HMX and TNT given in Figure 5 were 86.12 and 85.43 , respectively.
The degradation efficiency was $99.9 \%$ in the experiments conducted with octol, which could be explained by the higher initial concentration of total organic material that increased the removal efficiency. García-Jarana et al. (2013) found similar results and showed that the effect of the initial organic concentration on removal efficiency was more significant, especially in the low concentration ranges.

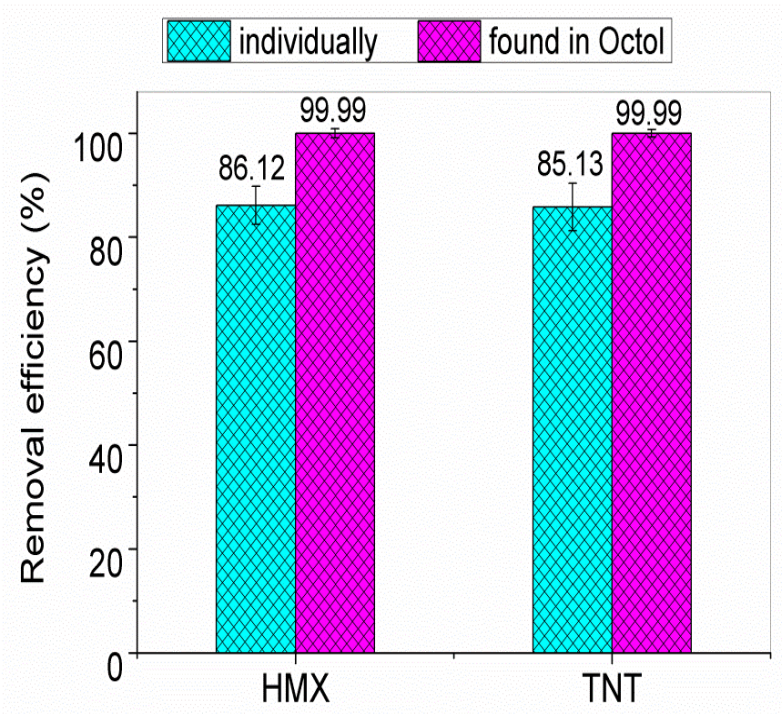

Figure 5. Comparison of degradation efficiency of octol components (HMX and TNT) individually and together in octol

Table 2. By-products of individual HMX and TNT degradation via SCWO

\begin{tabular}{cccc}
\hline \multirow{2}{*}{ By-Products } & \multirow{2}{*}{ Retention Time (min) } & \multicolumn{2}{c}{ Peak Area Ratio (\%) } \\
\cline { 3 - 4 } & & HMX Degradation & TNT Degradation \\
\hline Styrene & 4.38 & 1.18 & - \\
\hline Benzenamine & 5.67 & 5.13 & - \\
\hline Undecane, 4,7-dimethyl- & 6.87 & 1.08 & - \\
\hline Dodecane, 2,6,11-trimethyl- & 10.14 & 1.21 & 1.76 \\
\hline Hexadecane & 12.98 & 1.29 & - \\
\hline Nonadecane, 2-methyl- & 15.48 & 1.14 & 29.65 \\
\hline Trinitrotoluene Isomer & 15.58 & - & 4.39 \\
\hline P-Toluidine, 3,5-Dinitro- & 17.95 & 1.23 & 2.33 \\
\hline Octadecanoic acid & 19.92 & 21.54 & - \\
\hline Octadecanoic acid, trimethylsilyl ester & 24.24 & - & 19.21 \\
\hline 13-Docosenamide & 24.89 & & \\
\hline
\end{tabular}

In addition, when the by-product formation was considered at optimum conditions for octol degradation, as clearly seen in Table 2: (i) the TNT oxidation reaction was not complete, the isomerization reaction occurred simultaneously and p-Toluidine, 3,5-Dinitro and 13Docosenamide were dominant species even though found in trace amounts; (ii) when the degradation of the $\mathrm{HMX}$ compound was taken into account, however, styrene, benzenamine and other species were observed more frequently; (iii) the by-products of individual HMX and TNT degradation via SCWO were also found to be toxic (Table 2); and (iv) it could be concluded that both the isomerization and pyrolysis reactions took place simultaneously with the oxidation reactions. 


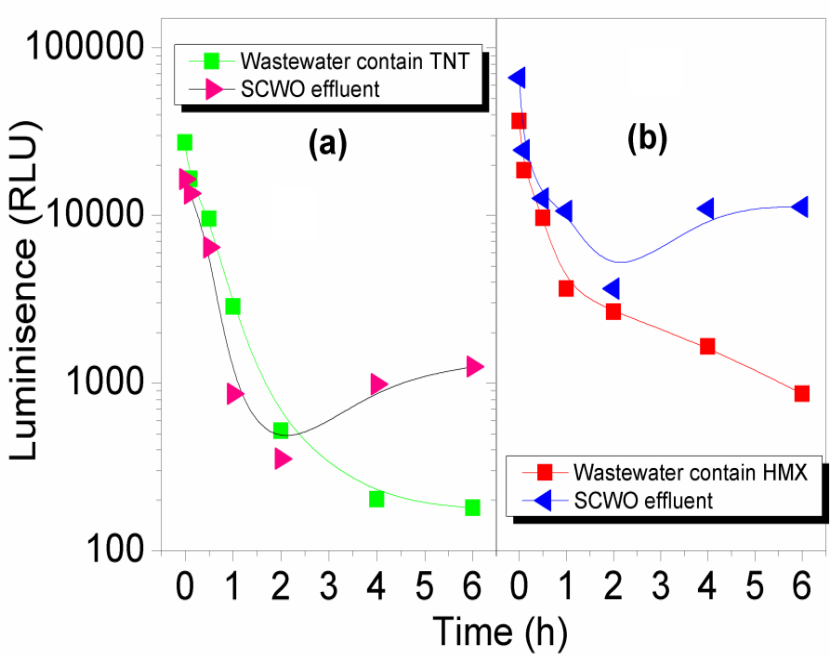

Figure 6. Results of microbial toxicity assay for degradation of (a) TNT and (b) HMX individually

Finally, the results of the toxicity tests are also presented in Figure 6. It was anticipated that the removal efficiency of the substances would show similar increasing trends for toxicity with increasing time, especially for up to $2 \mathrm{~h}$. However, these changes were not as significant as expected due to the formation of toxic by-products (Table 2).

\section{Conclusions}

In this study, the treatment of three different wastewaters containing octol, HMX and TNT via supercritical water oxidation (SCWO) was investigated for the first time. Pilot scale experiments were performed under different operating conditions which included temperature, reaction time and oxidant amount. Octol, HMX and TNT removal efficiency, by-product analysis and toxicity tests were EPA-selected as performance criteria. According to the experimental results, the following conclusions were drawn:

- The removal efficiency of octol, TNT and HMX strongly depended on temperature, oxidant amount and reaction time. Under optimum conditions determined as $500{ }^{\circ} \mathrm{C}, 120 \mathrm{~s}$ oxidation time and $150 \%$ oxidant ratio, $99.99 \%$ removal was achieved of octol manufactured by the casting of water-wet HMX and molten TNT, while TNT and HMX existing in wastewater were removed individually at a rate of $\sim 85 \%$.

- At the end of the octol oxidation, low molecular weight alcohols and acids were formed in trace amounts, which indicated the reaction had been nearly completed, and no toxicity (based on the recombinant $E$. coli cell test) was observed in the effluent, in spite of the TNT/HMX mixture showing higher synergistic toxic effects compared to the individual substances (TNT or HMX) (Panz et al., 2013). The SCWO also achieved a superior performance in the toxicity reduction of the mixture of these substances.
- The degradation of TNT and HMX individually exhibited effluent toxicity compared to the octol due to the TNT isomer, p-Toluidine, 3,5-Dinitro, 13-Docosenamide from the degradation of the TNT and Styrene and Benzenamine formation from $\mathrm{HMX}$ degradation as by-products which could have resulted from the isomerization and uncompleted oxidation reactions under the same operating conditions.

Finally, higher initial organic material concentrations were found to increase the oxidation reaction rates, which are primarily responsible for the performance of the SCWO. These results implied that the SCWO can be effectively used for octol degradation in similar military wastewater due to the high degradation rates and very low toxicity levels in effluents from the SCWO process.

\section{Acknowledgements}

The SCWO System was set up by MAES Limited Company supported by the Small and Medium Business Development and Support Administration (KOSGEB) Research Fund 910228.

\section{References}

Alnaizy R. and Akgerman A. (1999), Oxidative treatment of high explosives, Water Research, 33, 2021-2030. doi: 10.1016/S0043-1354(98)00424-2.

Alshammari Y.M. and Hellgardt K. (2015), Partial oxidation of nhexadecane through decomposition of hydrogen peroxide in supercritical water, Chemical Engineering Research and Design, 93, 565-575, doi: 10.1016/j.cherd.2014.05.025.

ATSDR (1995), Toxicological Profile for 2, 4, 6-Trinitrotoluene.

ATSDR (1997), Toxicological Profile for Hmx.

Chang S. and Liu Y. (2007), Degradation mechanism of 2,4,6trinitrotoluene in supercritical water oxidation, Journal of Environmental Sciences, 19, 1430-1435. doi: 10.1016/S10010742(07)60233-2.

Chatterjee S., Deb U., Datta S., Walther C. and Gupta D.K. (2017), Common explosives (TNT, RDX, HMX) and their fate in the environment: emphasizing bioremediation. Chemosphere, 184, 438-451, doi: 10.1016/j.chemosphere.2017.06.008.

Croiset E., Rice S.F. and Hanush R.G. (1997), Hydrogen peroxide decomposition in supercritical water, AlChE Journal, 43, 2343-2352. doi: 10.1002/aic.690430919.

Cui B., Cui F., Jing G., Xu S., Huo W. and Liu S. (2009), Oxidation of oily sludge in supercritical water, Journal of Hazardous Materials, 165, 511-517, doi: 10.1016/j.jhazmat.2008.10. 008.

Ding Z.Y., Frisch M.A., Li L.X. and Gloyna E.F. (1996), Catalytic oxidation in supercritical water, Industrial \& Engineering Chemistry Research, 35, 3257-3279. doi: 10.1021/ie9600 $22 n$.

EPA (1988), I. Chronic Health Hazard Assessments for Noncarcinogenic Effects.

Falone S.Z., Vieira E.M., Onuska F.I. (2006), Adsorption study of RDX and TNT explosives in soils by HPLC, Journal of Liquid Chromatography \& Related Technologies, 29, 1645-1662. doi: $10.1080 / 10826070600678373$.

García-Jarana M.B., Kings I., Sánchez-Oneto J., et al. (2013), Supercritical water oxidation of nitrogen compounds with multi-injection of oxygen, Journal of Supercritical Fluids, 80, 23-29, doi: 10.1016/j.supflu.2013.04.004. 
Hussein A.K., Elbeih A., Zeman S. (2018), Thermo-analytical study of a melt cast composition based on cis-1,3,4,6tetranitrooctahydroimidazo- $[4,5$ d] imidazole $\quad(\mathrm{BCHMX}) /$ trinitrotoluene (TNT) compared with traditional compositions, Thermochimica Acta, 666, 91-102, doi: 10.1016/j.tca.2018.06.006.

li E. (2015), Resources, Environment and Engineering II, CRC Press.

Jimenez-Espadafor F., Portela J.R., Vadillo V., et al. (2011), Supercritical Water Oxidation of Oily Wastes at Pilot Plant: Simulation for Energy Recovery, 775-784.

Jong M.Y., Van Aken B., Schnoor J.L. (2006), Leaching of contaminated leaves following uptake and phytoremediation of RDX, HMX, and TNT by poplar, International Journal of Phytoremediation, 8, 81-94. doi: 10.1080/1522651050050 7128.

Marulanda V., Bola G. (2010), Supercritical water oxidation of a heavily PCB-contaminated mineral transformer oil: laboratory-scale data and economic assessment, Journal of Supercritical Fluids, 54, 258-265. doi: 10.1016/j.supflu.2010. 04.008.

Nehrenheim E., Odlare M. (2008), Treatment Of Explosives Contaminated Water By Using Pine Bark In A Batch Process Potentials And Kinetics, 2nd International Conference on Hazardous and Industrial Waste Management.

Panz K., Miksch K., Sójka T. (2013), Synergetic toxic effect of an explosive material mixture in soil, Bulletin of Environmental Contamination and Toxicology, 91, 555-559, doi: 10.1007/ s00128-013-1090-8.

Qian L., Wang S., Xu D., Guo Y., Tang X., Wang L. (2016), Treatment of municipal sewage sludge in supercritical water: A review. Water Research, 89, 118-131, doi: 10.1016/ j.watres.2015.11.047.

Rodgers J.D., Bunce N.J. (2001), Treatment methods for the remediation of nitroaromatic explosives, Water Research, 35, 2101-2111. doi: 10.1016/S0043-1354(00)00505-4.

Sagi-Ben Moshe S., Ronen Z., Dahan O., Weisbrod N., Groisman L., Adar E., Nativ R. (2009), Sequential biodegradation of TNT, RDX and HMX in a mixture, Environmental Pollution, 157, 2231-2238. doi: 10.1016/j.envpol.2009.04.012.

Segond N., Matsumura Y., Yamamoto K. (2002), Determination of ammonia oxidation rate in sub- and supercritical water, Industrial \& Engineering Chemistry Research, 41, 6020-6027. doi: 10.1021/ie0106682.

Snellinx Z., Nepovim A., Taghavi S., Vangronsveld J., Vanek T., van der LelieLeile D. (2002), Biological remediation of explosives and related nitroaromatic compounds. ESPR, 9, 48-61.

Son H.S., Lee S.J., Cho I.H., Zoh K.D. (2004), Kinetics and mechanism of TNT degradation in $\mathrm{TiO}_{2}$ photocatalysis, Chemosphere, 57, 309-317. doi: 10.1016/j.chemosphere. 2004.05.008.

Brinkmann T., Giner Santonja G., Yükseler H., Serge Roudier L.D.S. (2016), Best Available Techniques (BAT) Reference Document for Common Waste Water and Waste Gas Treatment/Management Systems in the Chemical Sector, EUR 28112 EN.

Vadillo V., Sánchez-Oneto J., Portela J.R., Martínez de la Ossa E.J. (2014), Supercritical water oxidation for wastewater destruction with energy recovery, Supercritical Fluid
Technology for Energy and Environmental Applications, 181190, doi: 10.1016/B978-0-444-62696-7.00009-5.

Wang S., Guo Y., Wang L., Wang Y., Xu D., Ma H. (2011), Supercritical water oxidation of coal: Investigation of operating parameters' effects, reaction kinetics and mechanism, Fuel Processing Technology, 92, 291-297, doi: 10.1016/j.fuproc.2010.09.010.

Zhang S., Zhang Z., Zhao R., Gu J., Liu J., Örmeci B., Zhang J. (2017), A review of challenges and recent progress in supercritical water oxidation of wastewater, Chemical Engineering Communications, 204, 265-282. doi: 10.1080/ 00986445.2016.1262359. 